non-irritating food, without alcohol; life in temperate climates, avoiding cold and exposure. As to drugs, I counsel the use of chloride of ammonium, in doses of twenty or thirty grains, with nitro-hydrochloric acid, and perhaps strychnine. We shall try the inunction of biniodide of mercury ointment, so as to secure smart counter-irritation. In private life, recourse to the waters of Carlsbad, Vichy, or Kissingen would be desirable.

As to prognosis, we may look forward to a fairly good result. This man will never be a thoroughly robust or sound man. You would reject him were he a candidate for life assurance, because it would be an improper speculation for a sound society to take such a risk. But apart from that ordeal, you may, as his attendant, think better of him, and determine to persevere with treatment for years, if need be. In its further course, you might do well to try iodides of potassium and iron from time to time. I doubt if mercurials would much assist in a case of this kind. In any case, you may feel sure that the better the general health, and the higher the level of general nutrition you secure, the better it will be for the particular condition of the liver.

(The patient left the hospital a few weeks subsequently, greatly improved in general health, and having gained weight. He proposed to return to his duties at sea.)

The next case I direct your attention to, is that of C. D., aged 45, a country labourer. You notice at once that he is much jaundiced, a spare wiry-looking man. He came into Matthew Ward on October 26th. He tells us that he has always been healthy and active. In the beginning of August last he became jaundiced, and he thinks he was more yellow six weeks ago than now. He has suffered severely from prurigo with the jaundice, and you see over his trunk and extremities papules, which have been violently scratched. This is common enough in such cases, and is attributable to the irritation of biliary pigment and acids on sensory nerve twigs in the skin. His motions are white, and his urine bile-stained. There is no xanthopsy. He has had no pain whatever, and no vomiting or disturbance of digestion. His family history is unimportant, except as respects his father, who died of cancer of the tongue at the age of 60 . He gives a very uncertain history of syphilis at the age of 18 . He has never been abroad. In earlier life he drank freely of beer. His temperature is subnormal. In his thorax we find signs of slight general emphysema of the lungs. He suffers somewhat from cough in winter. A few rhonchi are audible over the lungs. The heart is natural, though a little overlapped by the left lung. The pulse is 60 , rather infrequent, as is common in jaundice. The arteries are thickened. The liver is very large, uniformly so, and smooth. The dulness begins at the seventh rib, and extends for eleven inches in the right nipple line to the level of the anterior superior iliac spine. The spleen is impalpable: There is neither ascites, enlarged abdominal veins, nor œdema of the legs. The urine is sp. gr. 1016, and void of albumen.

Here then is another example of a painless hepatic enlargement without ascites, but with jaundice. What is the cause of it? In the first place, there is pressure somewhere on the biliary ducts. This has come on insidiously, and it is of an abiding nature. Patients with chronic jaundice are apt to waste from interference with hepatic metabolism, and diversion of bile from the alimentary canal. You may thus be led to suspect malignant disease when there is none. Is there such here? This man's father died of cancer of the tongue. But there are two factors against the likelihood of it in this case. First, his age is somewhat early for cancer, and there is no pain. These are neither absolutely against the idea of malignant disease, but they count for something. We can exclude blocking of the common duct by gall-stones, for there is no history of this and the gall-bladder is not palpable. The long history of the case tells against simple catarrh of the upper bowel and gall-ducts. It is a somewhat obscure case. There may be some new growth in the fissure of the liver, or in the head of the pancreas compressing the commonduct. There may be a small hydatid tumour causing the same symptoms. In neither case would you look for pyrexia, and the biliary disturbance explains the wasting if the latter be the cause. I do not believe that the whole organ is infiltrated with new growth, and I regard the hypertrophy as due to a biliary cirrhosis or fibrosis. This may follow on an abiding source of pressure, as we know by the results of direct experiments on animals when the common duct is ligatured.

For treatment we must be content to employ such a diet as can best be digested, avoiding excess of hydrocarbons, as fat and sugar. We are giving ox-gall in capsules after meals, and at present employing the benzoate of sodium in full doses (gr. xv) thrice daily.

Warm alkaline and carbolic acid baths and carbolized ointment best relieve the intolerable itching.

Chloride of ammonium and bicarbonate of sodium are amongst the best drugs we know of to aid in such a condition, and we must wait and wateh for any new developments or indications.

The prognosis is not satisfactory in view of the history of the case. General wasting and loss of strength are likely to follow, and we have, I fear, not much to hope for. Nevertheless, now and then I have been agreeably surprised to find patients I had condemned live on for many years and carry on their duties fairly well, not as rural labourers certainly, but in some light avocation; and it is not justifiable to make either for oneself, or for the patient and his friends, too gloomy a prognosis, till by long observation we feel satisfied that the outlook is really hopeless.

\section{AN ADDRESS ON}

\section{SOME OF THE MORE UNUSUAL PHENOMENA} OF EPILEPSY. ${ }^{1}$

By S. WIIJKS, M.D., F.R.S., Consulting Physician to Guy's Hospital.

I NEED scarcely remark how unsystematic is our nomenclature of disease. Some diseases have for their appellations an anatomical basis, whilst others are named after a group of symptoms, or, rather, after the most prominent of the symptoms. This method is more satisfactory than the other, as it does not tie us to any pathological fact from which there is never afterwards any escape. If we see a combination of symptoms, which is repeated over and over again in different persons, we are warranted in giving a distinct appellation to that group. Having done this, we ask ourselves, Are we bound to require the presence of every one of those symptoms to constitute the disease? We say no; but then comes the more difficult question, Which are the essential ones? Take, for example, exophthalmic goître; we have all agreed to give this name in any particular case, even if the eye is not affeoted, the other symptoms of the disease being present. We have also agreed to do the same, under like circumstances, even if the thyroid be unaffected. I myself go further than this, and believe I see the same affection when neither throat nor eye is involved, so that we have in fact the play of Hamlet without Hamlet. When I see, for example, a patient much wasted, with very quick pulse, sweating, etc., and relieved by the same remedies which cure Graves's disease, I believe I have pathologically this complaint to deal with.

Now, as regards epilepsy. No disease is more characteristic in its typical form, that is, where a person falls downs with a loss of consciousness, followed by convulsions, and terminating in a deep sleep. One of our latest writers, and I should also say in this (Guy's) hospital a great authority -I mean Dr. Frederick Taylor, in his Manual of Medicine-still keeps to the definition. There is no doubt that as a definition, and applicable to the majority of cases, this is good; but when one takes in the whole field of possible examples of the disease we find a difficult in so restricting the name. That'the definition is generally good is seen from the faot that where a local lesion is found in the brain, which is not the case in ordinary epilepsy, there may be no loss of consciousness during the fit. So it may be said we have a different disease to deal with. And yet it is this very case which prevents us

1 Read at a meeting of the South London District of the Metropolitan Counties Branch of the British Medical Association. 
adopting the definition; for even should there be a local disease, as a gumma, it not infrequently happens that the convulsions are general, and the unconsciousness is complete. It would, therefore, be difficult to separate two cases, because the symptoms vary when the anatomical basis is the same in both. I believe. therefore, the highest authorities would not deny the use of the term epilepsy, even if the convulsion were partial, and no loss of consciousness occurred. The loss of consciousness has always been considered the most important symptom of the two, and all writers have included the petit mal- the case where there is a sudden loss of consciousness and no other symptom -under true epilepsy. So that, as in exophthalmic goître, both symptoms which are often said to characterise the disease may be absent. We may have epilepsy, though there may be respectively no loss of consciousness or no convulsion. We shall presently ask whether both of these may be absent in the same case, and yet we be warranted in calling it epilepsy.

A great deal of what I say has long been admitted, since in undoubted epileptics we witness attacks where nothing more is present than a strange feeling in the limbs or a sudden pain in some part of the body; in others an aberration of the senses or perturbation of an important organ, and sometimes only a strange mental disturbance. Now any of these phenomena may constitute the main feature in the case, and if they occur where there is a history of any attack of the graver form we have no difficulty in interpreting the symptoms and giving the name epilepsy. Frequently,however, patients come to us without any such history, and if they are unaccompanied by relatives or friends we have no corroborative evidence of the correctness of the tale, and we find ourselves in a difficulty in pronouncing upon the nature of the case.

I need scarcely allude to 'instances with which every medical man is familiar, where the aura constitutes the main symptom, or, at least, is that of which the patient has most knowledge. Some curious cases of this sort have come before my notice. A little girl was said to have occasional stabbing pains in her head, coming on at intervals and without warning, and in consequence she was thought to have some serious disease of the brain. Whilst sitting in a chair by my side she suddenly called out with pain in her head, and fell back unconscious with convulsive movements of the face and other symptoms of epilepsy.

Dr. Sutton related a case where a man was treated for angina pectoris owing to a sudden pain occurring in the chest. When carefully watched, he was seen to be an epileptic. A middle-aged man came to me complaining of sudden attacks of sickness; when his wife subsequently called on me and described other symptoms, it was clear that the vomiting was the onset of a mild epileptic attack. A very curious case was sent me of a young man whom the doctor was treating for syphilitic symptoms; he was said to have a syphilitic sore on the tongue, which, strangely enough, every two or three weeks broke out bleeding in the night, which woke the patient. What he really was suffering from were epileptic seizures in the night in which he bit his tongue. A clergyman came to me saying he had sudden loss of sight. Whilst reading the service in church, this would momentarily occur, but it immediately passed off, and he would continue reading. On close questioning, he would not admit the existence of any other symptom. I subsequently heard that he had had two most violent epileptic fits.

Then, again, the aberration or confusion of ' mind is well known. I had an epileptic friend who would become confused as he walked along the street, and then perhaps fall down. At other times he would continue walking, and behave so strangely that the police would have to take charge of him. In this condition the patient may be guilty of violence or do some eccentric act, as in the case of a young man who some years ago shot a girl without any reason. He said afterwards that he was quite unaware of what he had done, and, as corroborating his statement, he had a fit in the course of his trial. Another patient was driving out in his gig as usual, when he went in the wrong direction, and then continued driving about without aim or object until the boy who was with him started him home. The boy gave a description of his master's eccentric conduct; the latter knew nothing of it.
Simple falling, as in petit mal, might be syncope, but in both cases it is probably due to sudden diminution of blood in the brain. If the brain be for a moment deprived of its proper allowance of blood, unconsciousness occurs, and the patient falls; this was was shown by Sir A. Cooper in animals on ligaturing the cerebral vessels. In those cases where the whole brain suffers from diminished circulation, loss of consciousness occurs with paralysis of the whole body. In like manner, should a part of the brain be deprived of blood, there would be a temporary paralysis of the part of the body which it rules over, but no loss of consciousness. The first case is seen in the petit mal, where a patient will become suddenly unconscious, and as rapidly recover. In that form of complaint known as Jacksonian epilepsy, where in a fit one side may be convulsed, but where there is no loss of consciousness, we believe part of the motor region is involved, and generally by a gumma. In this case we often find the convulsed limb remain for some time weak. Now we have only to suppose that this portion suddenly loses its function as does the whole brain in the petit mal, and we have the case of a sudden loss of power in the limb without convulsions. In these local affections we may have indeed a strange feeling, a convulsion and loss of power in succession, or have each separately. The truth of this proposition is proved by patients who tell us they have strange feelings in a limb, or movements coming on at intervals and without warning, and whom we know to be true epileptics. For example, a young woman, aged 25 , has had several epileptic fits, in which she was convulsed, bit her tongue, etc. This was preceded by a pain in the left foot, running up to the knee. She was put on the bromide and the fits ceased, but subsequently she had repeated attacks of pain in the leg, but these did not culminate in a fit. A girl, aged 15, had had several well marked epileptic fits, before they came on she frequently called out from pain in the left arm and leg. Besides these bad attacks she often had the pain and strange feelings in the arm and leg, but followed by nothing more. I know a young man who has had slight epileptic attacks preceded by an aura in the right arm. Sometimes as he walks in the street, he feels this sensation in the arm and throws it about, and by force of will avoids an attack. This is quite on a par with drawing a tight ligature around the arm and arresting a seizure.

Knowing all this, ought we to put in the category of epilepsy cases which come before us where no other than local symptoms such as these haveoccurred? Sometimes we prove we are perfectly justified in so doing by the subsequent event. A young man came to me saying he had violent attacks of shaking of his head coming on every few days. A medical man who knew himwell said he had no other symptom, but I believed they were epileptic in nature. I subsequently heard that he had had attacks of unconsciousness.

A middle-aged man came to me saying that for nearly two years he had been subject to strange feelings in his left arm and back of neck. He felt inclined to fall, but did not. I put (?) epilepsy to this case but did not see him again. Then there are other cases where the symptoms are not like the more ordinary ones attending fits, where sensation is more or less affected, but where there is simply loss of motor power. Of course, in a complete fit with loss of consciousness the patient falls, being totally paralysed, and loses all sensation.

The question arises, Can these occur in a partial way? My own opinion is that they can; and just as a blow on the head produces concussion accompanied by want of power of movement or of feeling of the whole body, so there might be a concussion of one half-producing a temporary paralysis of motion and sensation of one side, but without loss of consciousness ; and in same way spontaneously portions of the brain or upper part of the cord rnight become affected, giving rise to those conditions so often met with in epilepsy. A man, aged 50, said that for five years he had been subject to attacks of loss of feeling in his feet and legs; this sometimes proceeded to the arms. The attack came on without any warning.

Another patient, aged 50," came to me saying that two years before, whilst in his office and rising to meet a friend he fell down, but did not lose consciousness. He got up and walked to his chair. Soon afterwards, whilst shaving, the razor fell from his hand. Besides these attacks of momentary loss of power, he has whilst sitting a sensation like a galvanic current running up his back. In the night he has awoke and found 
one arm and leg quite numb. A clergyman came to me for falling of his jaw. It did not occur whilst talking, but whilst sitting quiet his jaw fell and sometimes quivered. Nothing local was discoverable as a cause. Another patient said that whilst walking he was suddenly seized with complete loss of power of his legs; indoors sometimes he would feel as if all power were going out of him, and he was quite unable to speak. His jaw dropped, and his wife, if present, held up his jaw until power returned. He was connected with the engineering department of a colliery, and he said it appeared to him as if the machinery of his body was working quite regularly when suddenly there was a reversal of the engine.

$A$ very remarkable case was that of a man, aged 30 , who complained of a sudden loss of power of his limbs. He first noticed this whilst driving; his arms fell, and the reins dropped out of his hand. He almost immediately recovered the power. At another time his legs suddenly gave way beneath him. Sometimes whilst speaking his power of articulation would suddenly go, and at other times other muscles of head would be affected : he could not swallow, spit, or cough, and he saw double. When he came to me he was well, and appeared a healthy young man. I saw him some months afterwards with a friend, and he said he still had the attacks, and quite lately he was carrying rather a heavy weight, when his legs gave way under him and he fell down.

I mention these cases in connection with epilepsy seeing that true epilepties have these strange attacks in their limbs. I would not, however, say that in all cases they were of the same nature, and had the same pathology as epilepsy, although they might be. As before said, when a person falls, his whole body paralysed, it is connected with loss of con. sciousness. It may occur in epilepsy, but the simplest case is that of syncope. Where in epilepsy one limb is especially affected, it is supposed to mark a local affection of the brain ; and so I take it that as in syncope the function of the whole brain has become momentarily in abeyance in these cases it is a partial cerebral syncope, or rather local. A local temporary paralysis may thus be compared with a local spasm, as when a person is suddenly seized with a lockjaw so that he cannot speak. I am fully aware that these temporary paralyses, having their origin both in the brain and cord, are met with in various organic diseases of these organs. I have seen them in general paralysis, and more than once in ataxia and other diseases of the spinal cord, called then reflex.

Having thus divided the epileptic attack into its several parts, and seen how each one may predominate, if not be the only symptom, I have now left for consideration the final one, which usually succeeds to the ordinary attack-the sleep, drowsiness, or coma. I now ask, May this be the only symtom of epilepsy? I have reason to think it may, and to this part of my subject I wish for the opinion of the society either for or against, as $I$ think nothing much has been written upon it. There may be those present who would object to coma forming the essential or only part of epilepsy, seeing it would not accord with their definition or theory of the disease ; but I am at present putting aside all considerations of this kind, making my paper purely clinical.

A young lady, aged 19, gradually became insensible, and fell into a deep sleep; when awoke went to sleep again. After interval of some weeks she had another attack, when she fell into a state of almost complete insensibility, and slept for hours. She has had similar attacks since. Nothing was observed in the shape of convulsion or twitching of the muscles before the coma came on; but on closely questioning her as to her feelings before these attacks, she said she sometimes experienced a strange feeling in her right arm, leg, and face.

A gentleman of middle age was under my care for symptoms of a syphilitic nature, having nodes on the head with much pain. He one day, whilst sitting at dinner with his niece who took charge of him. complained of feeling unwell and sleepy, and said he should go to bed. He walked upstairs and was assisted into bed; he soon fell into a deep sleep from which he could not be roused, and a medical man was sent for. He was found to be in a profound coma, so that nothing could rouse him. I then saw him and we all thought he was dying, but after about ten hours he became wakeful and shortly came to. On the following day he was again downstairs as usual. It was clear that nothing of an apo- plectic seizure could have occurred. About two or three weeks afterwards he was seized with a true epileptic fit, followed by profound coma, which lasted several hours, as in the previous attack. He again quite recovered, but subsequently had another. It occurred in the evening, when he began to feel heavy and went up to bed, and soon sank into a comatose state. He lay thus for several hours as before, and then recovered. His niece and his nurse, who were quite prepared for a fit, on the closest quastioning, declared he had no warning or premonitory symptom of any kind before the coma came on. The niece was always watching him, and is sure that the slightest twitching of the face would have been noticed by her. It seemed to her, and also to me, that he would fall exactly into the same coma as 'he did when he had the regular fit.

Now, if coma be the only symptom of epilepsy, we may ask whether a partial insensibility may be of the same nature. I have already alluded to the mental aberrations of epileptics -how they will walk about in a dazed condition and be guilty of strange acts, and how such mental states may sometimes be the only indication of the paroxysm. Now, I ask, may such a condition occur and have epilepsy for its nature and pathology without any other symptoms ever having existed: For example, a boy of 14 was brought to me, who was said to be intelligent and had obtained prizes at his school. In two years he had had several attacks of the following nature: $\mathrm{His}$ mother would observe that when he came home he would seem very dull, sit in a chair, and not speak except addressed. He would be led up to bed or led anywhere like an automaton or a person hypnotised. He had no fit and no loss of consciousness; had several attacks of this kind. The last having continued three days, she brought him to me. He sat down in my study and said nothing, except in short words when addressed. He walked into other rooms when I told him, and then came back, doing anything he was bid. He had no other objective symptoms whatever. I saw him some months afterwards, and heard that the attacks were less frequent and shorter. He was a bright, intelligent boy, and presented a complete contrast to the patient I had before seen.

Sometimes an epileptic fit seems, as it were, drawn out; then, of course, there is no sudden falling, as, for example, a young woman, aged 22 , had curious attacks, which her medical man supposed were of an epileptic nature for the last six years. Whilst in the streets or elsewhere, she would feel a numbness in the leg and arm on one side; this continued f $) r$ two or three hours followed by headache. Sometimes the sight would fail on one side, but she never lost herself. If the attack came on in the day, she was unfit to go on with her work, for as a rule she wanted to sleep for hours afterwards. If one could imagine a fit which is usually all over in so many minutes protracted for several hours, one gets a notion of this case. Another case somewhat similar was that of a young man engaged as a clerk, and who for the last six years has had strange attacks. He feels a numbness creeping over his leg or arm of one side, and sometimes vision fails on one side. This feeling may last two or three hours, and is then followed by headache, which also lasts some time, and then sleep comes on. If these attacks occur during the day, he is obliged t) desist from work, as he feels headachy, sleepy, and generally queer. He never loses his consciousness. What he described was an epileptic attack long drawn out, an attack in which all the symptoms were spread out over a length of time-the greater part of a day. If they had been compressed into a short period they would have constituted an ordinary epileptic fit. In his case there obviously could not have been any loss of consciousness.

Now, having mentioned a number of symptoms which may be of an epileptic nature, there remains another disorder which many authors think is closely allied, if not of the same nature as epilepsy. I mean migraine. For many years I have closely watched this subject, and I have no reason to support this view ; in fact, my own experience is opposed to it. The main reason which authors have in associating the two is that the two complaints are both paroxysmal, and therefore they become placed together under the same heading in medical works. But periodic attacks of complaints in no way make them allied; and then in these two particular cases how different are the paroxysms. In one case the attack may come 
on suddenly, without any warning, so that the patient falls down in the streets, or into the fire; whilst in the other case the headache may be coming on for hours before it reaches its climax. This suddenness in epilepsy shows the attack is not anticipated, whereas an attack of migraine may be not only foretold, but produced at will. Many persons tell me that sitting in an atmosphere containing much carbonic acid will invariably produce an attack; others say a visit to a picture gallery will induce it; others the smell of flowers. I do not see myself the slightest resemblance between a symptom brought on at any time by an act of the will, and another which shows a periodic explosion of the brain occurring only at given intervals. This fact alone in my mind shows a complete separation of the two complaints. Then the symptoms have nothing in common; in the one there is the violent convulsion, dilated pupil, congestion, and often heat of body ; in the other a cold skin, contracted pupil, sickness, etc. Then it is said that, although they thus differ in outward phenomena, they may own the same cause and replace one another. This is a question of observation and fact. For my part I have no experience of it. I know a large number of migrainous persons and migrainous families, but I do not see megrim and epilepsy replace one another. The epileptic does not suffer from headache. This fact I arrived at many years ago, after the discovery of syphilitic disease of the cranium, of the membranes or surface of the brain, producing fits. For in these cases a local pain is present, and therefore it constitutes a diagnostic difference between these and simple epilepsy. It has therefore always been an inquiry on my part as to the existence of pain, and it may be stated as an absolute fact that the ordinary epileptic does not suffer from pain in his head. Then it is again said that if the two complaints do not occur together they may be seen in the same family, one member having the one complaint and another member the other. I have no knowledge of this, but, on the contrary, believe that the migrainous patient and the epileptic belong to a different class of persons. It is true that both affections are nervous, but the migraine occurs in persons of highly-strung nervous system - in the neurasthenic-whilst epilepsy occurs in persons who show no such tendency, but often in the dull and stupid. I have seen it somewhere written that migraine is a disease of the upper classes, and I think there must be some truth in this; for if I take men, I do not remember ever prescribing for the complaint amongst our out-patients, whilst epilepsy is common enough; nor can I understand how it could occur amongst them; and what would happen if our soldiers, sailors, policemen, and engine-drivers had attacks of migraine which for some hours would quite incapacitate them from their duties; and yet I never heard a man being declared unfit for these duties from having headache. If I wished to find epileptics, I should go to lunatic asylums or idiot asylums amongst the low and undeveloped; and, on the other hand, seek amongst the bright and intellectual for migraine; and if, moreover, I wanted to gain any information about the complaint, I should read the Philosophical Transactions, where are recorded the histories of many distinguished men who suffered from it.

I have now cursorily alluded to various phenomena associated with the disease known as epilepsy. Many of these are well known, and need not be further commented upon. The part of my paper on which I should like the opinion of the meeting is that where coma is spoken of as the only symptom, and also on that in which I have suggested that a fit may be drawn out or protracted over several hours. I should also like to hear the views of the meeting on the question of the alliance of epilepsy and migraine. I have stated my opinion as opposed to it; but since many distinguished authors have of late been in the habit of placing them together, I am quite open to any further observation or facts which may tend to strengthen the position they have taken.

Professor Emerich Navratil, the well-known laryngologist of Buda-Pesth, celebrated the silver jubilee of his career as a teacher in that seat of learuing recently. The anniversary was made the occasion for a series of "ovations" and festivities which bore striking testimony to the popularity of the Professor who so worthily bears the mantle of Czermak.
A N ADDRESS

ON

\section{THE METH0D OF ZADIG IN MEDICINE. \\ Delivered at the Inaugural Meeting of the North London Medical and Chirurgical Society.}

By T. LAUDER BRUNTON, M.D., D.Sc.EDIN., F.R.S., LL.D.(HoN.) ABERD., F.R.C.P.

Mr. President and Gentlemen,-I have first of all to thank you most heartily for the honour you have done me in asking me to address you to-night. The choice of a subject has not been easy, and in trying to select one it occurred to me that perhaps no animal gets to its goal more quickly or more surely than the carrier pigeon; yet when started on its homeward journey it does not fly directly onwards, but first of all takes two or three preliminary circles, in order to ascertain its whereabouts and the direction in which to direct its flight. The time spent in doing this is very far from lost, and what occurs in the case of the carrier pigeon appears to happen also in the conduct of human affairs. A little while ago I was down in the country, and a nurseryman, a most intelligent and able man, gave me a few lessons on pruning. $\mathrm{He}$ told me first of all what to avoid, and then what to do. "Some people," he said, "when they want to prune a tree begin with the knife at once, and cut here and there without having a definite idea of what they are to do. Now the proper way is to put your hands in your pockets, stand a little distance off, look at your tree, see what you want to do, and then set to work."

In laboratory researches we find the same thing, and a few preliminary experiments are often very advantageous in learning the methods of work, so that an apparent loss of time at the beginning is often a real saving both of time and trouble in the end. Now, as this is a new jociety, it seemed to me that perhaps it might be better, instead of beginning with a definite medical subject, such as the pathology and treatment of some disease, to ask you rather to direct your thoughts to some general methods of investigation. Now one of the greatest losses in medicine is the loss of individual experience. We find that men most able and successful in the practice of their profession, in the recognition and in the treatment of disease, die and carry their knowledge away with them. Some men may record the cases they have seen, but comparatively few are able to record their experience in such a way as to make it thoroughly available for others. Various attempts have been made at different times to collect the experiences of medical men, especially those in general practice, and to put it in such a form as to be available for their colleagues.

In the years 1874-77, ${ }^{1}$ in my capacity of Editor of the Practitioner, I made an attempt to collect the experiences of practitioners by issuing a circular and asking for returns regarding the treatment of quinsy and sciatica. Answers were returned from all parts of the world, and these were collated and published. The advantage which was gained, however, seemed hardly enough to repay the time, trouble, and expense which these questions and returns necessitated, and the attempt was discontinued. A few years later another attempt was made on a very much larger scale by the Collective Investigation Committee of the British Medical Association, but after this had been continued for a while it was also dropped. The same desire for the collection of information is shown, however, in the union of medical men to form societies in which everyone shall profit by the experience of his neighbour. The formation of the present Society is another indication of the value of this form of collective investigation; and it seems to me rather important that at its commencement we should pause a while and take a glance round before proceeding with what one may term its proper work-the consideration of diseases. and their treatment.

' Practitioner, November, 1874, vnl. xiii, p 3c8; rol xvi, p. 41; and vol xviii, p. iot. 